\title{
Lumican expression in advanced colorectal cancer with nodal metastasis correlates with poor prognosis
}

\author{
TOMOKO SEYA ${ }^{1}$, NORITAKE TANAKA ${ }^{1}$, SEIICHI SHINJI ${ }^{1}$, KIMIYOSHI YOKOI $^{1}$, \\ MICHIHIRO KOIZUMI ${ }^{1}$, NOBUHISA TERANISHI ${ }^{2}$, KIYOHIKO YAMASHITA $^{2}$, \\ TAKASHI TAJIRI ${ }^{2}$, TOSHIYUKI ISHIWATA ${ }^{3}$ and ZENYA NAITO ${ }^{3}$
}

\author{
${ }^{1}$ Department of Surgery, Chiba Hokusoh Hospital Nippon Medical School, 1715 Kamagari, Inba, Chiba 270-1694; \\ ${ }^{2}$ Department of Surgery for Organ and Biological Regulation (Department of Surgery I), Graduate School of \\ Medicine, Nippon Medical School, 1-1-5 Sendagi, Bunkyo-ku, Tokyo 113-8603; ${ }^{3}$ Department of \\ Integrative Pathology (Department of Pathology II), Graduate School of Medicine, \\ Nippon Medical School, 1-1-5 Sendagi, Bunkyo-ku, Tokyo 113-8602, Japan
}

Received June 19, 2006; Accepted September 11, 2006

\begin{abstract}
Lumican is a member of a small leucine-rich proteoglycan family, and it is reportedly overexpressed in human breast cancer. The expression of lumican in the extracellular matrix in breast cancer is associated with a high tumor grade, low estrogen receptor levels and young age. Lumican expression has been previously reported in colorectal cancer, but the role of lumican in the tumor is not well understood. In this study, we examined the expression and role of lumican in advanced colorectal cancer. Immunohistochemical staining was performed on 158 patients who underwent curative surgery for advanced colorectal cancer with lymph node metastasis. In the normal colorectal tissues, lumican immunoreactivity was observed in the fibroblasts and neural cells, but not in the colorectal epithelial cells. Lumican was localized in the cytoplasm of the cancer cells and its overexpression was detected in 99 of the $158(62.7 \%)$ colorectal cancer patients. Clinicopathologically, there was no association of lumican expression with age, sex, histological typing, or venous and lymphatic invasion. However, lumican expression tended to correlate with the spread of lymph node metastasis and the depth of tumor invasion ( $\mathrm{p}=0.136$ and 0.135 , respectively). Furthermore, the survival rate was significantly lower in patients with a high lumican expression level than in those with a low lumican expression level $(\mathrm{p}=0.048)$. These results indicate that lumican expression is a potential prognostic factor in patients with advanced colorectal cancer with nodal metastasis.
\end{abstract}

Correspondence to: Dr Tomoko Seya, Department of Surgery, Chiba Hokusoh Hospital, Nippon Medical School, 1715 Kamagari, Inba, Chiba 270-1694, Japan

E-mail: seya@nms.ac.jp

Key words: colorectal cancer, lumican, immunohistochemistry

\section{Introduction}

Lumican belongs to a family of small leucine-rich proteoglycans (SLRPs), which have core proteins of $\sim 40 \mathrm{kD}$ and possess 6-10 leucine-rich repeats (between flanking cysteinerich disulfide-bonded domains that are the $\mathrm{N}$ and $\mathrm{C}$ termini of the core protein) (1-4). In addition to lumican, SLRPs include keratocan, mimecan, decorin, biglycan, fibromodulin, epiphycan, osteoadherin (5). The human lumican protein contains 338 amino acids, including a putative 18-residue signal peptide, and its gene is located on chromosome 12q21.3-q22 $(6,7)$. Lumican was first identified in the cornea as a keratan sulfate proteoglycan (KSPG) (4), and in noncorneal tissues, lumican exists as a low or non-sulfated glycoprotein (7-9). Lumican was then reported to be present in the extracellular matrix of many tissues, such as the skin, lung, intervertebral disk, skeletal muscle, kidney, pancreas, brain, placenta, heart, aorta, liver, and the intestine (7,9-14).

Mice, homozygous for null mutation in lumican, displayed corneal opacification and skin laxity (15). In the corneal tissue, lumican was reported to regulate the assembly and diameter of the collagen fibers (4). Lumican is considered a key regulator of collagen fibrillogenesis, a process critical to corneal transparency. Several studies have shown that SLRP proteins can modulate cellular behaviors, including cell migration and proliferation during embryonic development, tissue repair, and tumor growth, in addition to their extracellular matrix functions as regulators of tissue hydration and collagen fibrillogenesis (16).

In breast cancer tissues, lumican is overexpressed in the fibroblasts adjacent to the cancer cells. Its high expression level is further associated with a high tumor grade, low estrogen receptor levels and young patients (17). In addition, as we have previously reported, in human pancreatic, uterine cervical, and colorectal cancers, lumican is localized in the cancer cells, and the cancer cells as well as the fibroblasts adjacent to them, synthesize lumican mRNA and its protein $(14,18,19)$. In a colorectal cancer study, lumican was expressed in five of the five colorectal cancer cell lines and in the cancer 
Table I. The clinicopathological characteristics of the 158 colorectal cancer patients.

\begin{tabular}{|c|c|}
\hline Parameter & No. of patients \\
\hline \multicolumn{2}{|l|}{ Sex } \\
\hline Female/male & $67 / 91$ \\
\hline \multicolumn{2}{|l|}{ Age } \\
\hline Range & $26-86$ \\
\hline Mean & 63.1 \\
\hline \multicolumn{2}{|c|}{ Histological typing } \\
\hline Well & 81 \\
\hline Moderate & 62 \\
\hline Mucinous & 9 \\
\hline Poor & 6 \\
\hline \multicolumn{2}{|l|}{ Location } \\
\hline Colon & 78 \\
\hline Rectum & 80 \\
\hline \multicolumn{2}{|c|}{ Macroscopic findings } \\
\hline 1 & 13 \\
\hline 2 & 121 \\
\hline 3 & 24 \\
\hline \multicolumn{2}{|c|}{ Depth of tumor invasion } \\
\hline $\mathrm{mp}$ & 24 \\
\hline ss, a1 & 63 \\
\hline $\mathrm{s}, \mathrm{a} 2$ & 71 \\
\hline \multicolumn{2}{|c|}{ Lymph vessel invasion } \\
\hline ly $(-)$ & 17 \\
\hline ly $(+)$ & 141 \\
\hline \multicolumn{2}{|c|}{ Venous vessel invasion } \\
\hline $\mathrm{v}(-)$ & 60 \\
\hline $\mathrm{v}(+)$ & 98 \\
\hline \multicolumn{2}{|c|}{ Status of nodal metastasis } \\
\hline $\mathrm{n} 1$ & 91 \\
\hline $\mathrm{n} 2$ & 53 \\
\hline n3 & 14 \\
\hline
\end{tabular}

cells in eight of the 12 colorectal cancer patients (18). However, the exact role of lumican in human colorectal cancer remains unclarified.

In this study, we examined lumican expression in advanced colorectal cancer with lymph node metastasis, and determined the correlations of its expression with the clinicopathological factors.

\section{Patients and methods}

Patients and tissue samples. One hundred and fifty-eight patients who underwent curative surgery for advanced colorectal cancer with lymph node metastasis from 1984 to 1997

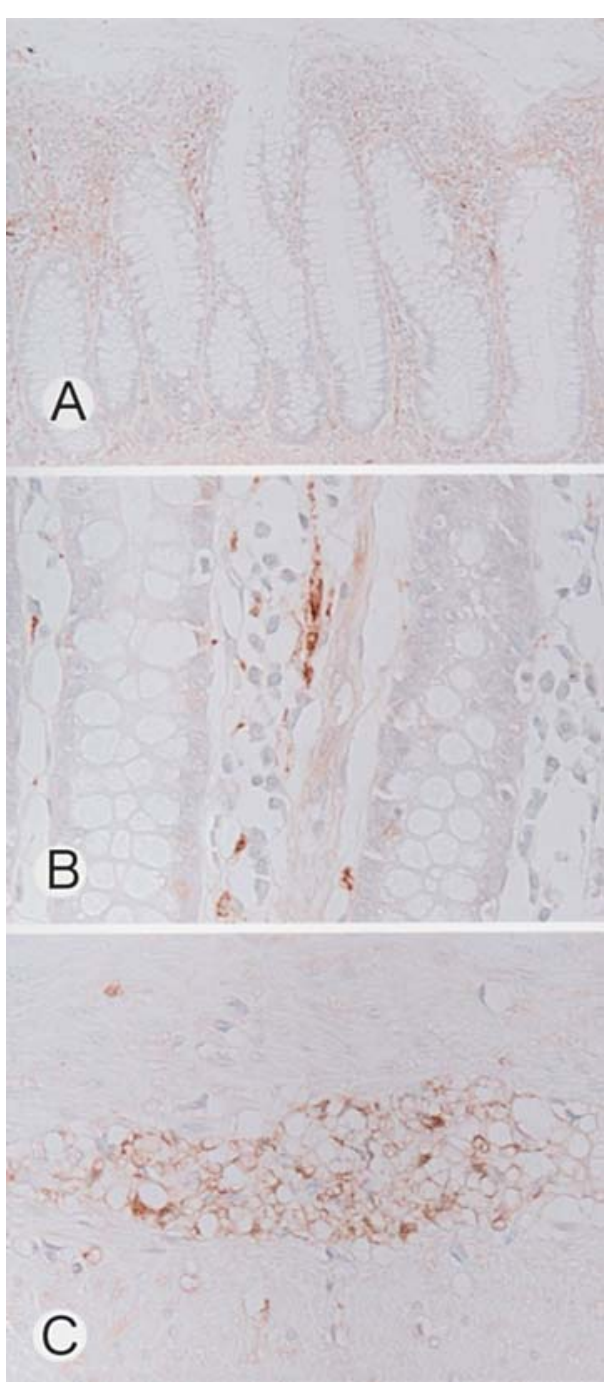

Figure 1. Immunohistochemical analysis of lumican in normal colorectal tissues. Lumican was not localized in the epithelial cells (A), but was weakly positively localized in the fibroblasts (B) and neural cells (C) in the normal colorectal tissues. Original magnification x200 (A); x400 (B and C).

at Nippon Medical School participated in this study. After being fixed in $10 \%$ neutral buffered formalin for $18-20 \mathrm{~h}$, the colorectal cancer tissues were embedded in paraffin, serially sectioned at $3 \mu \mathrm{m}$ and stained with $\mathrm{H} \& \mathrm{E}$ for light microscopy. The clinicopathological characteristics of the patients (sex, age, histological typing, tumor location, macroscopic findings, depth of tumor invasion, lymphatic and venous invasions and the occurrence of lymph node metastasis) are summarized in Table I.

Immunohistochemistry. The polyclonal antibody against the human lumican protein used for immunohistochemistry was obtained as previously reported (12). Immunohistochemical analysis was performed using the Histofine Simple Stain $\mathrm{PO}^{\circledR}$ Max kit (Nichirei, Tokyo, Japan). After deparaffinization, endogenous peroxidase activity was blocked by incubation in $0.3 \%$ hydrogen peroxide in methanol for $30 \mathrm{~min}$. The tissue sections were incubated with the anti-human lumican antibody (1:500) in phosphate-buffered saline (PBS) containing $1 \%$ bovine serum albumin (BSA) for $16 \mathrm{~h}$ at $4^{\circ} \mathrm{C}$. Bound 


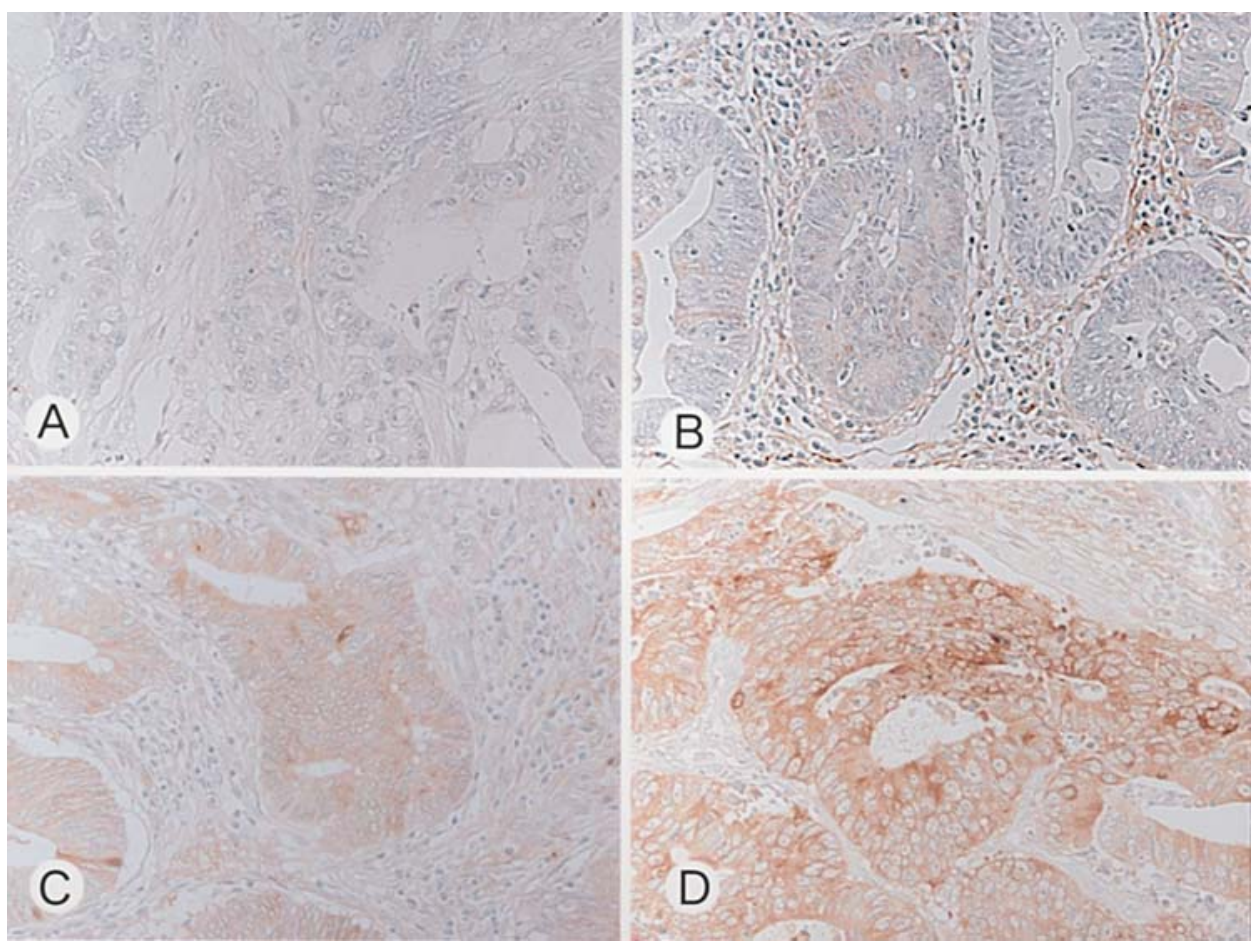

Figure 2. The characteristic staining pattern of lumican in the cytoplasm of colorectal cancer cells. The intensities of lumican immunoreactivity in the colorectal cancer cells were classified into four groups, namely, negative (A), weakly positive (B), positive (C) and strongly positive (D). Original magnification x200.

antibodies were detected with the Simple Stain $\mathrm{PO}^{\circledR}$ Max reagent using diaminobenzidine tetrahydrochloride as the substrate, and the sections were counterstained with Mayer's hematoxylin. To confirm the specificity of the primary antibodies, the anti-lumican antibodies were preincubated with a blocking peptide for lumican for $1 \mathrm{~h}$ and then applied to the sections, which showed no positive immunoreactivity.

Estimation of lumican expression level in colorectal cancer. The correlations of lumican expression with the clinicopathological factors were analyzed according to the Japanese classification of colorectal carcinoma (20). The immunoreactivity of the lumican protein was scored on the basis of the intensity of the predominant cytoplasmic staining area using the following classification system: $0=$ negative; $1=$ weakly positive; 2 = positive and $3=$ strongly positive. To examine the associations of the lumican expression level with the clinicopathological features or the prognostic factors, the tumors were divided into two groups according to the intensity of staining, that is, scale 0 as the negative group and scales 1-3 as the positive groups. All the specimens were evaluated by two investigators (T.S. and N.T.) who were unaware of the clinical information of the patients.

Statistical analysis. Mann-Whitney tests were used to compare the quantitative and ordered variables, and the Student's t-test was used to analyze the differences in the normally distributed data between the two groups. The Chisquare test and Fisher's test were used to analyze the associations of lumican expression with the prognostic factors. The survival rate was calculated by the Kaplan-Meier method, and the significance of the difference in the survival rate was analyzed by the log-rank test. A P-value of $<0.05$ was considered statistically significant.

\section{Results}

Localization of lumican in colorectal cancer. In the normal colorectal tissues, the epithelial cells showed no staining for lumican, but the fibroblasts and neural cells showed positive staining for lumican (Fig. 1A-C). In the colorectal cancer tissues, lumican was diffusely localized in the cytoplasm of the cancer cells and was detectable in 99 of the $158(62.7 \%)$ colorectal cancer patients. The intensities of lumican immunoreactivity were classified into four groups, namely, negative, weakly positive, positive and strongly positive (Fig. 2A-D). In most lumican-positive tumors, lumican immunoreactivity was heterogeneous with a patchy distribution in the colorectal cancer cell nests. The cancer cells infiltrating the lymph follicle were intensely stained, and the staining was intense at the invasive front of the cancer cells (Fig. 3A and B).

Correlations of lumican expression with clinicopathological factors. Lumican expression did not correlate with sex, age, tumor location, or venous and lymphatic invasion (Table II). The associations of the lumican intensity score with the clinicopathological factors are summarized in Table III. Semiquantitative analysis showed that ulcerated tumors had more intensive staining for lumican than protuberant tumors (1.24 vs 0.79). Moreover, ulcerated tumors with infiltrative growth showed particularly higher staining intensity scores (1.42). Based on the extent of lymph node metastasis, the lumican expression level is elevated in advanced colorectal cancer cases $(n 1,0.97 ; n 2,1.25$; and $n 3,1.29)$. As for the 


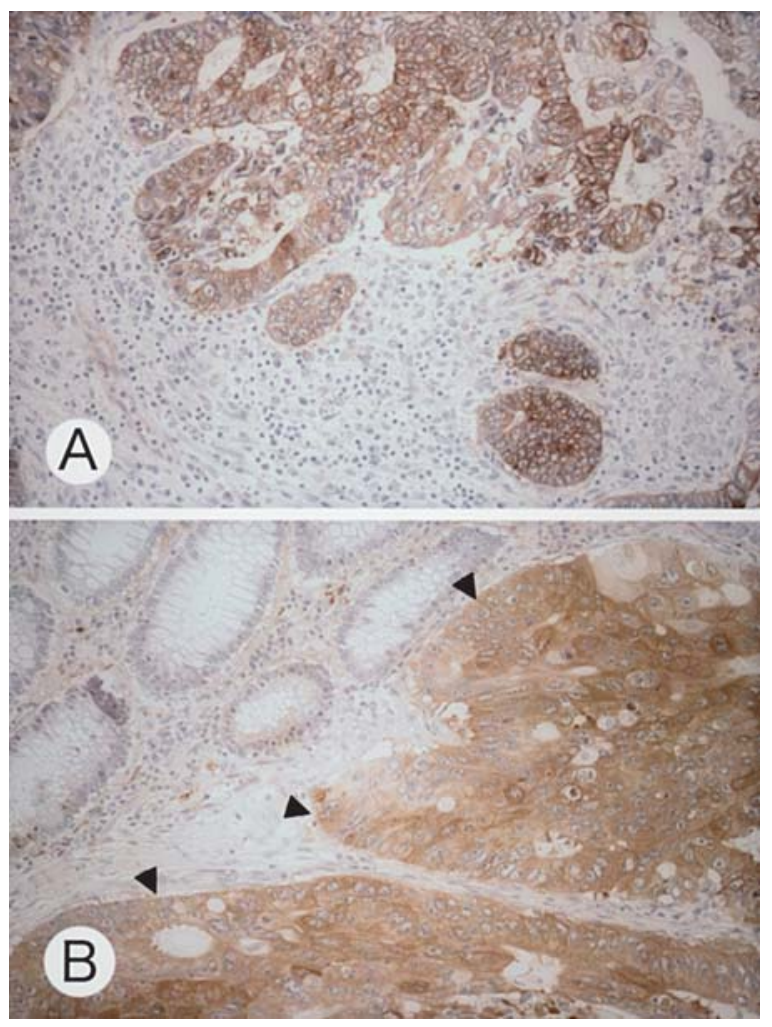

Figure 3. Immunohistochemical analysis of lumican in the colorectal cancer tissues adjacent to the lymph follicle. The cancer cells infiltrating the lymph follicle were intensely stained (A), and staining was intense at the invasive front of the cancer cells (B, arrowheads). Original magnification x200.

histological typing, moderately differentiated adenocarcinoma showed the most intensive lumican staining (1.31) compared with other tumors (well differentiated adenocarcinoma, 0.99; poorly differentiated adenocarcinoma, 0.67; and mucinous adenocarcinoma, 1.17). An elevated lumican expression level was positively associated with the depth of tumor invasion as shown in Table III. Tumors invading the muscularis propria had higher intensity scores than those restricted to the muscularis propria (1.16 vs 0.67 ). As a result, there was an association between lumican expression and the histological stage (stage 1lla, 0.98; and stage 1llb, 1.24).

Poor prognosis in patients with high lumican expression level. The prognosis between the patients with lumicanpositive and lumican-negative tumors was compared (Fig. 4). The survival rates of the patients with lumican-positive tumors were significantly lower than those of the patients with lumican-negative tumors ( $\mathrm{p}=0.048)$.

\section{Discussion}

The most intensive staining of lumican was shown in the cancer cells infiltrating the lymph follicles and at the invasive front of the cancer cells. Funderburgh et al demonstrated that the nonsulfated form of the lumican protein promoted macrophage attachment and spreading (21). This action is thought to be mediated by a lumican receptor expressed by macrophages (18). The finding that colorectal cancer cells infiltrating the lymph follicles showed the highest lumican expression
Table II. Lumican expression vs the clinicopathological parameters of the 158 colorectal cancer patients.

\begin{tabular}{|c|c|c|c|}
\hline Parameter & $\begin{array}{l}\text { Lumican } \\
(+)\end{array}$ & $\begin{array}{c}\text { Lumican } \\
(-)\end{array}$ & P-value \\
\hline \multicolumn{4}{|l|}{ Sex } \\
\hline Female & 42 & 25 & \multirow[t]{2}{*}{$0.99^{a}$} \\
\hline Male & 57 & 34 & \\
\hline \multicolumn{4}{|l|}{ Age } \\
\hline$\leq 40$ & 2 & 1 & \multirow{6}{*}{$0.77^{\mathrm{b}}$} \\
\hline $41-50$ & 14 & 4 & \\
\hline $51-60$ & 23 & 18 & \\
\hline $61-70$ & 32 & 21 & \\
\hline $71-80$ & 27 & 12 & \\
\hline$>80$ & 1 & 3 & \\
\hline \multicolumn{4}{|c|}{ Histological typing } \\
\hline Well & 45 & 36 & \multirow{4}{*}{$0.12^{\mathrm{a}}$} \\
\hline Moderate & 46 & 16 & \\
\hline Mucinous & 5 & 4 & \\
\hline Poor & 3 & 3 & \\
\hline \multicolumn{4}{|l|}{ Location } \\
\hline Colon & 48 & 30 & \multirow[t]{2}{*}{$0.77^{\mathrm{a}}$} \\
\hline Rectum & 51 & 29 & \\
\hline \multicolumn{4}{|c|}{ Macroscopic findings } \\
\hline 1 & 9 & 4 & \multirow{3}{*}{$0.952^{\mathrm{b}}$} \\
\hline 2 & 74 & 47 & \\
\hline 3 & 16 & 8 & \\
\hline \multicolumn{4}{|c|}{ Depth of tumor invasion } \\
\hline $\mathrm{mp}$ & 12 & 12 & \multirow{3}{*}{$0.135^{\mathrm{b}}$} \\
\hline ss, al & 40 & 23 & \\
\hline $\mathrm{s}, \mathrm{a} 2$ & 47 & 24 & \\
\hline \multicolumn{4}{|c|}{ Lymph vessel invasion } \\
\hline ly (-) & 12 & 5 & \multirow[t]{2}{*}{$0.47^{a}$} \\
\hline ly $(+)$ & 87 & 54 & \\
\hline \multicolumn{4}{|c|}{ Venous vessel invasion } \\
\hline $\mathrm{v}(-)$ & 41 & 19 & \multirow[t]{2}{*}{$0.25^{\mathrm{a}}$} \\
\hline $\mathrm{v}(+)$ & 58 & 40 & \\
\hline \multicolumn{4}{|c|}{ Status of nodal metastasis } \\
\hline $\mathrm{nl}$ & 53 & 38 & \multirow{3}{*}{$0.136^{\mathrm{b}}$} \\
\hline $\mathrm{n} 2$ & 35 & 18 & \\
\hline n3 & 11 & 3 & \\
\hline
\end{tabular}

${ }^{\mathrm{a} T h e}$ Chi-square, and ${ }^{\mathrm{b}}$ Mann-Whitney tests were used.

level further indicates that lumican expression mediates the interactions between the colorectal cancer cells and the cells constituting the lymph follicle. This interaction may play 
Table III. Patients' characteristics and intensity score for lumican.

\begin{tabular}{|c|c|c|c|c|c|c|}
\hline \multirow[b]{2}{*}{ Score } & \multicolumn{4}{|c|}{ Intensity score of lumican expression } & \multirow[b]{2}{*}{$\begin{array}{c}\text { Average } \\
\text { score }\end{array}$} & \multirow[b]{2}{*}{$\begin{array}{c}\text { Rank } \\
\text { correlation } \\
\text { coefficient }\end{array}$} \\
\hline & 0 & 1 & 2 & 3 & & \\
\hline \multicolumn{7}{|l|}{ Type } \\
\hline 1 & 6 & 6 & 1 & 1 & 0.79 & \multirow{3}{*}{0.098} \\
\hline 2 & 61 & 21 & 11 & 28 & 1.05 & \\
\hline 3 & 10 & 2 & 4 & 8 & 1.42 & \\
\hline \multicolumn{7}{|l|}{$\mathrm{N}$} \\
\hline $\mathrm{nl}$ & 47 & 18 & 8 & 18 & 0.97 & \multirow{3}{*}{0.11} \\
\hline $\mathrm{n} 2$ & 24 & 8 & 5 & 16 & 1.25 & \\
\hline n3 & 5 & 3 & 3 & 3 & 1.29 & \\
\hline \multicolumn{7}{|l|}{ Grade } \\
\hline Well & 45 & 11 & 8 & 18 & 0.99 & \multirow{4}{*}{0.083} \\
\hline Moderate & 23 & 15 & 6 & 18 & 1.31 & \\
\hline Mucinous & 3 & 1 & 0 & 2 & 1.17 & \\
\hline Poor & 5 & 2 & 2 & 0 & 0.67 & \\
\hline \multicolumn{7}{|l|}{ Depth } \\
\hline $\mathrm{mp}$ & 14 & 7 & 0 & 3 & 0.67 & \multirow[t]{2}{*}{0.129} \\
\hline $\mathrm{al}, \mathrm{a} 2, \mathrm{ss}, \mathrm{s}$ & 62 & 22 & 16 & 34 & 1.16 & \\
\hline \multicolumn{7}{|l|}{ Stage } \\
\hline IlIa & 47 & 18 & 9 & 18 & 0.98 & \multirow[t]{2}{*}{0.098} \\
\hline $111 b$ & 29 & 11 & 7 & 19 & 1.24 & \\
\hline
\end{tabular}

Spearman's rank correlation coefficients were used.

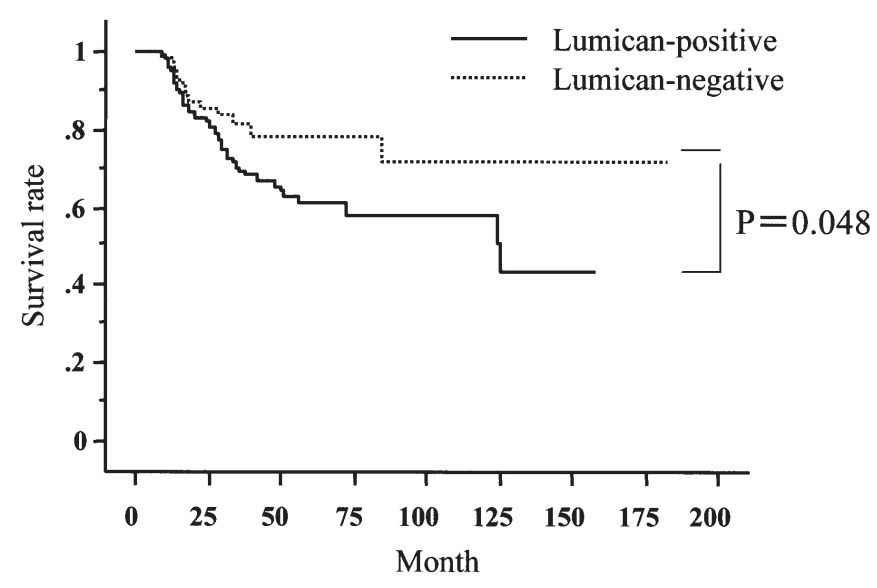

Figure 4. The prognosis of lumican-positive or lumican-negative advanced colorectal cancer patients with nodal metastasis. Kaplan-Meier survival curves for the patients with colorectal cancer showing a poorer survival in lumican-positive patients than in lumican-negative patients.

an important role in lymph node invasion. The role of macrophages in the lymph follicles must be examined more closely in the future.
In addition to lymph follicle infiltration, lumican showed intense staining at the invasive front of the cancer cells. Lumican expression at the invasive front of the cancer cells has been detected in other cancers. In uterine cervical cancer, the lumican protein was localized mainly at the periphery of the cancer cell nests (19). Furthermore, in breast cancer, an increased lumican deposition rate was observed in the collagenous stroma of the tumors, particularly at the margins of the invasive tumors (22). These accumulations of the lumican protein at the tumor invasive fronts may have important roles in cell growth and in the invasion of adjacent stromal tissues not only in uterine and breast cancers but also in colorectal cancer.

There are a few reports on lumican expression and the clinicopathological factors of cancer. In breast cancer, the lumican expression level correlates with cancer grade, the estrogen receptor level and patient age (17). In advanced colorectal cancer, lumican expression did not correlate with age, sex, tumor location or venous and lymphatic invasion. What are the differences between breast cancer and colorectal cancer concerning these factors? One possibility is that lumican in cancer tissues may play different roles in the stroma and cytoplasm. The side chains of lumican in the stromal tissues and the cytoplasm of cancer cells may be different. 
Another possibility is that hormonal circumstances induced by breast cancer may influence the expression and role of lumican. Recent studies showed that lumican plays important roles in tumor growth inhibition and that it is an apoptotic inducer $(23,24)$. To elucidate the role of lumican in cancer tissues, further molecular biological studies of colorectal cancer and clinicopathological studies of other cancers are needed.

In colorectal cancer, lumican expression tended to correlate with lymph node metastasis and the depth of tumor invasion. Furthermore, the survival rates in the patients with lumicanpositive tumors were significantly lower than those in the patients with lumican-negative tumors. These results indicate that lumican expression could be a prognostic factor for advanced colorectal cancer with lymph node metastasis.

\section{Acknowledgements}

The authors thank Ms. K. Kawahara, Ms. Y. Kawamoto and Mr. T. Fujii (Department of Integrative Pathology, Nippon Medical School) for their excellent technical assistance.

\section{References}

1. Krusius T and Ruoslahti E: Primary structure of an extracellular matrix proteoglycan core protein deduced from cloned cDNA. Proc Natl Acad Sci USA 83: 7683-7687, 1986.

2. Fisher LW, Termine JD and Young MF: Deduced protein sequence of bone small proteoglycan I (biglycan) shows homology with proteoglycan II (decorin) and several nonconnective tissue proteins in a variety of species. J Biol Chem 264: 4571-4576, 1989.

3. Oldberg A, Antonsson P, Lindblom K and Heinegard D: A collagen-binding 59-kd protein (fibromodulin) is structurally related to the small interstitial proteoglycans PG-S1 and PG-S2 (decorin). EMBO J 8: 2601-2604, 1989.

4. Blochberger TC, Vergnes JP, Hempel J and Hassell JR: cDNA to chick lumican (corneal keratan sulfate proteoglycan) reveals homology to the small interstitial proteoglycan gene family and expression in muscle and intestine. J Biol Chem 267: 347-352, 1992.

5. Fullwood NJ, Davies Y, Nieduszynski IA, Marcyniuk B, Ridgway AE and Quantock AJ: Cell surface-associated keratan sulfate on normal and migrating corneal endothelium. Invest Ophthalmol Vis Sci 37: 1256-1270, 1996.

6. Chakravarti S, Stallings RL, SundarRaj N, Cornuet PK and Hassell JR: Primary structure of human lumican (keratan sulfate proteoglycan) and localization of the gene (LUM) to chromosome 12q21.3-q22. Genomics 27: 481-488, 1995.
7. Grover J, Chen XN, Korenberg JR and Roughley PJ: The human lumican gene. Organization, chromosomal location, and expression in articular cartilage. J Biol Chem 270: 21942-21949, 1995.

8. Wight TN, Kinsella MG and Qwarnstrom EE: The role of proteoglycans in cell adhesion, migration and proliferation. Curr Opin Cell Biol 4: 793-801, 1992.

9. Ying S, Shiraishi A, Kao CW, et al: Characterization and expression of the mouse lumican gene. J Biol Chem 272: 30306-30313, 1997.

10. Sztrolovics R, Alini M, Mort JS and Roughley PJ: Age-related changes in fibromodulin and lumican in human intervertebral discs. Spine 24: 1765-1771, 1999.

11. Saika S, Shiraishi A, Liu CY, et al: Role of lumican in the corneal epithelium during wound healing. J Biol Chem 275: 2607-2612, 2000.

12. Baba H, Ishiwata T, Takashi E, Xu G and Asano G: Expression and localization of lumican in the ischemic and reperfused rat heart. Jpn Circ J 65: 445-450, 2001.

13. Qin H, Ishiwata T and Asano G: Effects of the extracellular matrix on lumican expression in rat aortic smooth muscle cells in vitro. J Pathol 195: 604-608, 2001.

14. Ping Lu Y, Ishiwata T and Asano G: Lumican expression in alpha cells of islets in pancreas and pancreatic cancer cells. J Pathol 196: 324-330, 2002.

15. Chakravarti S, Magnuson T, Lass JH, Jepsen KJ, LaMantia C and Carroll H: Lumican regulates collagen fibril assembly: skin fragility and corneal opacity in the absence of lumican. J Cell Biol 141: 1277-1286, 1998

16. Iozzo RV and Wight TN: Isolation and characterization of proteoglycans synthesized by human colon and colon carcinoma. J Biol Chem 257: 11135-11144, 1982.

17. Leygue E, Snell L, Dotzlaw H, et al: Expression of lumican in human breast carcinoma. Cancer Res 58: 1348-1352, 1998.

18. Lu YP, Ishiwata T, Kawahara K, et al: Expression of lumican in human colorectal cancer cells. Pathol Int 52: 519-526, 2002.

19. Naito Z, Ishiwata T, Kurban G, et al: Expression and accumulation of lumican protein in uterine cervical cancer cells at the periphery of cancer nests. Int J Oncol 20: 943-948, 2002.

20. Yasutomi M, Baba S, Hojo K, et al: Japanese Society for Cancer of the Colon and Rectum: Japanese Classification of Colorectal Carcinoma. Tokyo Kanehara \& Co., Ltd., 1997.

21. Funderburgh JL, Mitschler RR, Funderburgh ML, Roth MR, Chapes SK and Conrad GW: Macrophage receptors for lumican. A corneal keratan sulfate proteoglycan. Invest Ophthalmol Vis Sci 38: 1159-1167, 1997.

22. Leygue E, Snell L, Dotzlaw H, et al: Lumican and decorin are differentially expressed in human breast carcinoma. J Pathol 192: 313-320, 2000.

23. Watanabe T, Komuro Y, Kiyomatsu T, et al: Prediction of sensitivity of rectal cancer cells in response to preoperative radiotherapy by DNA microarray analysis of gene expression profiles. Cancer Res 66: 3370-3374, 2006.

24. Vuillermoz B, Khoruzhenko A, D'Onofrio MF, et al: The small leucine-rich proteoglycan lumican inhibits melanoma progression. Exp Cell Res 296: 294-306, 2004. 